\title{
Study on the priority of coronary arteriography or therapeutic hypothermia after return of spontaneous circulation in patients with out-of-hospital cardiac arrest: results from the SOS-KANTO 2012 study
}

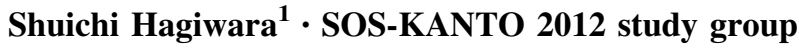

Received: 13 September 2015/Accepted: 12 December 2015/Published online: 1 February 2016

(C) The Author(s) 2016. This article is published with open access at Springerlink.com

\begin{abstract}
Many emergency physicians struggle with the clinical question of whether to perform therapeutic hypothermia (TH) or coronary angiography (CAG) first after return of spontaneous circulation (ROSC) in patients with out-of-hospital cardiac arrest (OHCA). We analyzed the results of the SOS-KANTO 2012 study, which is a prospective, multicenter (67 emergency hospitals), observational study about OHCA conducted between January 2012 and March $2013(n=16,452)$. We compared two groups: the group in which TH was first performed (TH group), and the group in which CAG was performed first (CAG group) within $24 \mathrm{~h}$ after arrival. Two hundred and twenty-one patients were treated TH and CAG (TH group, 76 patients; CAG group, 145 patients). In addition, we selected patients who underwent coronary treatment. 164 patients underwent coronary treatment after CAG (TH group, 52 patients; CAG group, 112 patients). In patients in whom $\mathrm{TH}$ and CAG and coronary artery treatment were done, 42 patients $(55.3 \%)$ in the TH group and 86 patients $(59.3 \%)$ in the CAG group survived at 90 days. The cerebral performance category (CPC) 1 and 2 were $26.3 \%$ (20 patients) in $\mathrm{TH}$ group, and $31.0 \%$ (45 patients) in CAG group. In patients in whom $\mathrm{TH}$ and CAG with coronary artery treatment were performed, 29 patients $(55.8 \%)$ in the TH group and 64 patients $(57.1 \%)$ in the CAG group survived at 90 days. The rates of CPC 1 and 2 were $26.9 \%$ (14 patients)
\end{abstract}

The SOS-KANTO 2012 study group members are listed in Appendix section.

Shuichi Hagiwara

shuhagiwara@gunma-u.ac.jp

1 Department of Emergency Medicine, Gunma University

Graduate School of Medicine, 3-39-22 Showa-machi,

Maebashi, Gunma 371-8511, Japan in TH group, and $23.2 \%$ (26 patients) in CAG group. There was no significant difference in 90-day survival between the two groups although it tended to be better in the CAG group than in the TH group. Whether TH or CAG was performed first did not affect the 90-day survival and 30-day neurological situation among patients with ROSC after OHCA.

Keywords Therapeutic hypothermia - Coronary angiography · Out-of-hospital cardiac arrest

\section{Introduction}

Out-of-hospital cardiac arrest (OHCA) is one of the greatest problems of community and public health. For patients with OHCA to have a good prognosis, it is essential not only to resuscitate precisely, but also to perform post-cardiac arrest care appropriately after return of spontaneous circulation (ROSC).

In post-cardiac arrest care, therapeutic hypothermia $(\mathrm{TH})$ is a helpful approach for protection of the brain and other organs in patients who remain comatose after ROSC $[1,2]$. TH may be considered for comatose adult patients with ROSC after OHCA according to the 2010 American Heart Association (AHA) Guidelines for Cardiopulmonary Resuscitation (CPR) and Emergency Cardiovascular Care (ECC) [3]. Those guidelines recommend that the body temperature should be cooled to $32-34{ }^{\circ} \mathrm{C}$ for $12-24 \mathrm{~h}$ in $\mathrm{TH}$.

On the other hand, the usefulness of emergent coronary angiography (CAG) in survivors of OHCA has already been reported [4, 5], and the 2010 AHA Guidelines for CPR and ECC insist that emergent CAG may be reasonable because of the high incidence of acute coronary ischemia in OHCA patients [3]. In particular, percutaneous coronary intervention (PCI), alone or as part of a bundle of care, is 
associated with improved myocardial function [4] and neurological outcomes [5, 6]. However, the priority of TH or CAG has not been established yet. So there are doctors who are worried about the risk of pulmonary edema in using low temperature hypothermia [7], and do not believe there is convincing evidence to support the use of hypothermia prior to CAG. Such doctors think TH (including cooling blanket and ice packs) should start after CAG/PCI. This study was projected for such doctors to provide more evidence of early or simultaneous $\mathrm{TH}$ and CAG.

A Survey of Survivors of OHCA in the Kanto district of Japan 2012 study (SOS-KANTO 2012 study) was performed by the Japanese Association for Acute Medicine in Kanto district between January 2012 and March 2013, and included 67 emergency hospitals and emergency medical services units (26 academic medical centers). The SOSKANTO 2012 study was a prospective, multicenter, observational study about OHCA.

We evaluate the priority of TH or CAG after ROSC in patients with OHCA using the data of the SOS-KANTO 2012 study.

\section{Methods}

The SOS-KANTO 2012 study was a prospective, multicenter (67 emergency hospitals), observational study conducted between January 2012 and March 2013 on patients with OHCA. The protocol of the SOS-KANTO 2012 study was approved without the need for informed consent by the research ethics board of Yokohama City University Medical Center (Yokohama, Kanagawa, Japan; D1402005). The total number of OHCA patients who were transferred to the 67 emergency hospitals (26 academic medical centers), and the emergency hospitals that participated in the SOS-KANTO 2012 study are listed in Acknowledgments. The results of SOS-KANTO 2012 study are published in several journals [8-11].

The study flow diagram is shown in Fig. 1. First, we selected OHCA patients who underwent both TH and CAG after ROSC within $24 \mathrm{~h}$ after arrival at the hospital from all OHCA patients. Patients $\leq 18$ years were excluded. Patients with missing data were also excluded. Then, these patients were divided into the following two groups: (1) $\mathrm{TH}$ was performed first prior to CAG (TH group), and (2) CAG was performed first prior to TH (CAG group). Next, we analyzed the patients who were treated with coronary artery stenting. In this study, we defined CAG as only coronary artery imaging using catheter.

The indications for CAG and coronary artery treatment in patients with OHCA were decided by emergency physicians and cardiologists at each hospital. TH was defined as maintenance of core body temperature at $32-34{ }^{\circ} \mathrm{C}$ for $12-24 \mathrm{~h}$ after ROSC, and the methodology of TH was entrusted to each hospital.

The primary outcomes were 90-day survival and neurological status, and the secondary outcomes were 30-day neurological status and complications associated with $\mathrm{TH}$. Neurological status was described by cerebral performance category (CPC) [12, 13]. Good neurological outcome was defined as $\mathrm{CPC} 1$ and $\mathrm{CPC} 2$.

\section{Statistical analysis}

Differences between the groups were analyzed with Student's $t$ test for normally distributed variables or MannWhitney $U$ test for non-normally distributed variables, and the Fisher's exact test for categorical variables. Survival curves were drawn by the Kaplan-Meier method, and were compared with the log-rank test.

IBM SPSS Statistics 22 and EZR (Saitama Medical Center, Jichi Medical University, Saitama, Japan) were used for statistical analyses. EZR is a graphical user interface for R (The R Foundation for Statistical Computing, Vienna, Austria). More precisely, it is a modified version of $\mathrm{R}$ commander designed to add statistical functions frequently used in biostatistics [14]. Statistical significance was assumed to be present at a $p$ value of $<0.05$.

\section{Results}

During the study period, 16,452 patients were collected in the SOS-KANTO 2012 study.

As shown in Fig. 1, both TH and CAG were performed within $24 \mathrm{~h}$ after arrival at the hospital in 221 patients. TH was performed first in 76 patients (TH group), and CAG was performed first in 145 patients (CAG group). Among them, there were 164 patients in whom the coronary arteries were treated (52 patients in $\mathrm{TH}$ group, and 112 patients in CAG group).

Table 1 shows the characteristics of patients in the TH $(n=76)$ and CAG $(n=145)$ groups who are with or without coronary treatment. There were 61 males in $\mathrm{TH}$ group, and 123 males in CAG group, respectively $(p=1)$. The mean age \pm standard deviation (SD) (years old) of $\mathrm{TH}$ group is $60.4 \pm 13.6$, that of CAG group is $63.1 \pm 11.2$, respectively $(p=0.11)$. The median time from arrival to CAG start $[ \pm$, interquartile range (IQR) (min) $]$ in TH group is $88.5 \pm 70.5$, in CAG group is $70.0 \pm 46.0$, respectively $(p=0.014)$. The median time from arrival to reach the target body temperature [ $\mathrm{I}$ IQR $(\mathrm{min})]$ in TH group is $155 \pm 249.5$, in CAG group is $300 \pm 225$, respectively $(p<0.001)$. The median time from TH start to reach the target body temperature [ \pm IQR (min)] in TH group is 
Fig. 1 The study flow diagram

SOS-KANTO 2012 study OHCA patients: $\mathrm{N}=16,452$

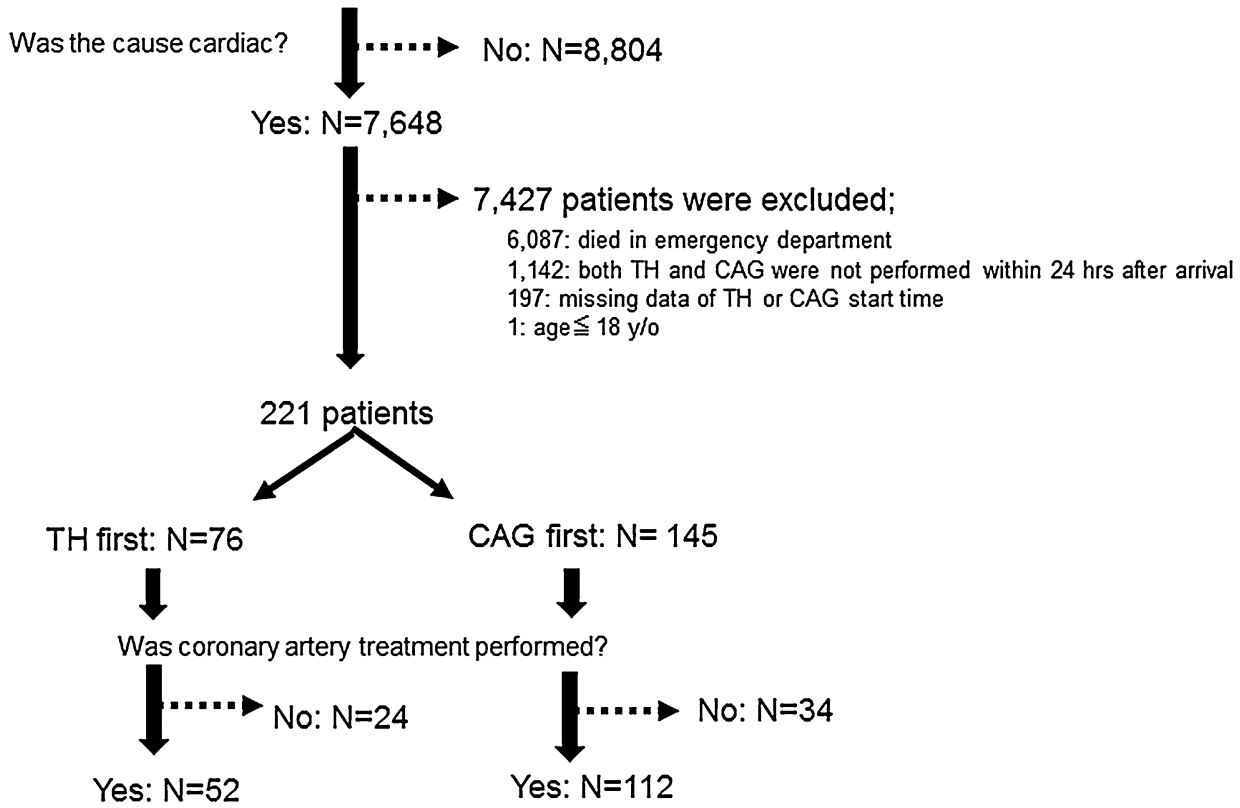

TH, therapeutic hypothermia; CAG, coronary angiography

Table 1 Patients' characteristics of the TH group and CAG group (TH and CAG with or without coronary artery treatment was performed in all patients)

\begin{tabular}{|c|c|c|c|}
\hline & TH group $(N=76)$ & CAG group $(N=145)$ & $p$ \\
\hline $\operatorname{Sex}(\mathrm{M} / \mathrm{F})(N)$ & $61 / 12$ & $123 / 22$ & 1 \\
\hline Mean age $($ years old $) \pm S D$ & $60.4 \pm 13.6$ & $63.1 \pm 11.2$ & 0.11 \\
\hline Median time from amvai to CAG start $[ \pm \mathrm{IQR}(\mathrm{min})]$ & $88.5 \pm 70.5$ & $70 \pm 46$ & 0.014 \\
\hline Median time from amvai to reach the target body temperature $[ \pm \mathrm{IQR}(\mathrm{min})]$ & $155 \pm 249.5$ & $300 \pm 225$ & $<0.001$ \\
\hline Median time from TH start to reach the target body temperature $[ \pm \mathrm{IQR}(\mathrm{min})]$ & $105 \pm 210$ & $161.5 \pm 154.6$ & 0.191 \\
\hline Witnessed $[N(\%)]$ & $61(80.3)$ & $115(79.3)$ & 1 \\
\hline by-stander CPR $[N(\%)]$ & $45(59.2)$ & $73(50.3)$ & 0.552 \\
\hline \multicolumn{4}{|l|}{ ECG waveform at first $[N(\%)]$} \\
\hline $\mathrm{VF} / \mathrm{VT}$ & $52(68.4) / 0(0)$ & $84(57.9) / 0(0)$ & 0.496 \\
\hline PEA & 7 (9 2) & $29(200)$ & 0.085 \\
\hline Asystole & $6(79)$ & $8(55)$ & 0.568 \\
\hline Other & $10\left(\begin{array}{ll}13 & 2\end{array}\right)$ & $24(166)$ & 0.698 \\
\hline \multicolumn{4}{|l|}{ ECG waveform arrival $[N(\%)]$} \\
\hline $\mathrm{VF} / \mathrm{VT}$ & $17(224) / 0(0)$ & $26(17.9) / 0(0)$ & 0.601 \\
\hline PEA & $14(184)$ & $32\left(\begin{array}{ll}22 & 1\end{array}\right)$ & 0.732 \\
\hline Asystole & $10(132)$ & $22\left(\begin{array}{ll}15 & 2\end{array}\right)$ & 0.843 \\
\hline Other & $35(461)$ & $65(448)$ & 1 \\
\hline With ECMO $[N(\%)]$ & $34(447)$ & $45\left(\begin{array}{ll}31 & 0\end{array}\right)$ & 0.177 \\
\hline With IABP $[N(\%)]$ & $41(539)$ & $73\left(\begin{array}{lll}50 & 3\end{array}\right)$ & 0.809 \\
\hline With BP $[N(\%)]$ & $4\left(\begin{array}{ll}5 & 3\end{array}\right)$ & $20(138)$ & 0.108 \\
\hline
\end{tabular}

$T H$ therapeutic hypothermia, $C A G$ coronary angiography, $S D$ standard deviation, $I Q R_{t}$ interquartile range, $C P R$ cardiopulmonary resuscitation, $E C G$ electrocardiogram, $V F / V T$ ventricular fibrillation pulseless ventricular tachycardia, $P E A$ pulseless electrical activity, $E C M O$ extracorporeal membrane oxygenation, $I A P B$ intra-aortic balloon pumping, $B P$ blood purification 
$105 \pm 210$, in CAG group is $161.5 \pm 154.6$, respectively $(p=0.191)$. There were $61(80.3 \%)$ patients with witnessed arrest in the TH group, and 115 (79.3\%) patients with witnessed arrest in the CAG group, respectively $(p=1)$. There were $45(59.2 \%)$ patients with by-stander CPR in the TH group, and $73(50.3 \%)$ patients with bystander CPR in the CAG group, respectively ( $p=0.552)$. There were $52(68.4 \%)$ patients who were in ventricular fibrillation/pulseless ventricular tachycardia (VF/VT) in the TH group, and there were $84(57.9 \%)$ patients that were in VF/VT in the CAG group in the electrocardiogram (ECG) wave form at first, respectively $(p=0.496)$. There were 17 $(22.4 \%)$ patients in VF/VT in the ECG wave form at arrival in TH group, and there were $26(17.9 \%)$ patients in CAG group, respectively $(p=0.601)$. There were 34 $(44.7 \%)$ patients who were treated with extra corporeal membrane oxygenation (ECMO) in the $\mathrm{TH}$ group, and there were $45(31.0 \%)$ patients who were treated ECMO in CAG group, respectively $(p=0.177)$. There were 41 $(53.9 \%)$ patients who were treated with intra-aortic balloon pumping (IABP) in the $\mathrm{TH}$ group, and there were 73 $(50.3 \%)$ patients who were treated with IABP in the CAG group, respectively $(p=0.809)$. There were $4(5.3 \%)$ patients who were treated with blood purification (BP) including hemodialysis (HD) or continuous hemodiafiltration (CHDF) in the TH group, and there were 20 (13.8\%) patients who were treated with $\mathrm{BP}$ in the CAG group, respectively ( $p=0.108)$.

Table 2 shows characteristics of the patients who received coronary artery treatment (52 patients in $\mathrm{TH}$ group, and 112 patients in CAG group). Fifty patients were treated with catheter, and 2 patients were treated other methods in the TH group, 109 patients were treated with catheter and 3 patients with other methods in the CAG group. There were 44 males in the TH group, and 96 males in the CAG group, respectively $(p=1)$. The mean age $\pm \mathrm{SD}$ (years old) of the $\mathrm{TH}$ group was $62.2 \pm 11.3$, that of the CAG group was $63.1 \pm 11.5$, respectively $(p=0.652)$. The median time from arrival to CAG start [土 (IQR) (min)] in the TH group was $83.5 \pm 65.3$, in the CAG group was $69.5 \pm 44.8$, respectively $(p=0.062)$. The median time from arrival to reach the target body temperature [士 IQR (min)] in the TH group is $147 \pm 243.8$, in the CAG group is $300 \pm 232.3$, respectively $(p<0.001)$. The median time from TH start to reach the target body temperature $[ \pm \mathrm{IQR}$ (min)] in the TH group is $120 \pm 192$, is $180 \pm 150$ in the CAG group, respectively $(p=0.259)$. There were $42(80.8 \%)$ patients with witnessed in the TH group, and $87(77.7 \%)$ patients with witnessed in the CAG group, respectively $(p=0.9)$. There were $30(57.7 \%)$ patients with by-stander CPR in the TH group, and $56(50.0 \%)$ patients with by-stander CPR in the
CAG group, respectively $(p=0.671)$. There were 35 $(67.3 \%)$ patients who were VF/VT in the TH group, and $62(55.4 \%)$ in VF/VT in the CAG group in the ECG wave form at first, respectively $(p=0.498)$. There were 10 $(19.2 \%)$ patients in VF/VT in the ECG wave form at arrival in the TH group, and there were $20(17.9 \%)$ patients in the CAG group, respectively ( $p=0.835)$. There were $22(42.3 \%)$ patients who were treated ECMO in the TH group, and there were $38(33.9 \%)$ patients who were treated with ECMO in the CAG group, respectively $(p=0.523)$. There were $31(59.6 \%)$ patients who were treated with IABP in the TH group, and there were 64 $(57.1 \%)$ patients who were treated with IABP in the CAG group, respectively $(p=0.891)$. There were $3(5.8 \%)$ patients who were treated with $\mathrm{BP}$ in the $\mathrm{TH}$ group, and there were $17(15.2 \%)$ patients who were treated with BP in the CAG group, respectively ( $p=0.194)$.

We could analyze the time from arrival to coronary reperfusion [coronary reperfusion was defined as thrombolysis in myocardial infarction (TIMI) grade 2 or 3] in only 124 patients (TH group: $N=37$, CAG group: $N=87$ ). The median time from arrival to coronary reperfusion $[ \pm \mathrm{IQR}(\mathrm{min})]$ is $162 \pm 73$ in the TH group, and $120 \pm 69$ in the CAG group, respectively $(p<0.001)$.

\section{Primary outcomes}

Figure 2a shows the Kaplan-Meier survival curves of patients in whom $\mathrm{TH}$ and $\mathrm{CAG}$ with or without coronary artery treatment were done. At 90 days, 42 patients $(55.3 \%)$ in the the TH group and 86 patients $(59.3 \%)$ in the the CAG group survived. Estimated mean survival day is 52.6 (standard error: 5.8, $95 \%$ confidence interval 41.2-63.9) days in the TH group and estimated mean survival day was 55.3 (standard error: 3.8, $95 \%$ confidence interval 47.8-62.8) days in the CAG group, respectively. Figure $2 \mathrm{~b}$ shows the Kaplan-Meier survival curves of patients in whom $\mathrm{TH}$ and $\mathrm{CAG}$ with coronary artery treatment were performed. At 90 days, 29 patients $(55.8 \%)$ in the $\mathrm{TH}$ group and 64 patients $(57.1 \%)$ in the CAG group survive. Estimated mean survival day is 51.6 (standard error: 4.8, $95 \%$ confidence interval 42.2-61.1) days in TH group, and estimated mean survival day is 56.9 (standard error: 3.3, $95 \%$ confidence interval 50.3-63.4) days in the CAG group, respectively. As shown in the two figures, there is no significant difference in 90-day survival between the two groups although it tended to be better in the CAG group than in the $\mathrm{TH}$ group.

Table 3 shows the 90-day neurological prognosis of patients. As shown in Table 3, there is no significant difference in the rate of patients with good neurological prognosis at 90 days between the two groups. 
Table 2 Patients' characteristics of the TH group and CAG group (TH and CAG with coronary artery treatment were performed in all patients)

\begin{tabular}{|c|c|c|c|}
\hline & TH group $(N=52)$ & CAG group $(N=112)$ & $p$ \\
\hline $\operatorname{Sex}(\mathrm{W} / \mathrm{F})(N)$ & $44 / 8$ & $96 / 16$ & 1 \\
\hline Mean age (years old $) \pm S D$ & $62.2 \pm 1.13$ & $63.1 \pm 11.5$ & 0.652 \\
\hline Median time from arrival to CAG start $[ \pm \mathrm{IQR}(\mathrm{min})]$ & $83.5 \pm 65.3$ & $69.5 \pm 44.75$ & 0.062 \\
\hline Median time from arrival to reach the target body temperature $[ \pm \mathrm{IQR}(\mathrm{min})]$ & $147 \pm 2438$ & $300 \pm 232.3$ & $<0.001$ \\
\hline Median time from TH start to teach the target body temperature $[ \pm \mathrm{IQR}(\mathrm{min})]$ & $120 \pm 192$ & $180 \pm 150$ & 0.259 \\
\hline Median time from arrival to coronary reperfusion $[ \pm \mathrm{IQR}(\mathrm{min})]$ & $162 \pm 73^{*}$ & $120 \pm 69 * *$ & $<0.001$ \\
\hline Witnessed $[N(\%)]$ & $42(80.8)$ & $87(77.7)$ & 0.9 \\
\hline By-stander CPR $[N(\%)]$ & $30(57.7)$ & $56(50)$ & 0.671 \\
\hline \multicolumn{4}{|l|}{ ECG waveform at first $[N(\%)]$} \\
\hline $\mathrm{VF} / \mathrm{VT}$ & $35(67.3) / 0(0)$ & $62(554) / 0(0)$ & 0.498 \\
\hline PEA & $6(115)$ & $24(214)$ & 0.278 \\
\hline Asystole & $2(3.8)$ & $6(5.4)$ & 1 \\
\hline Other & $9(17.3)$ & $20(17.9)$ & 1 \\
\hline \multicolumn{4}{|l|}{ ECG waveform at arrival $[N(\%)]$} \\
\hline VF/VT & $10(19.2) / 0(0)$ & $20(17.9) / 0$ & 0.35 \\
\hline PEA & $12(23.1)$ & $26(23.2)$ & 1 \\
\hline Asystole & $7(13.5)$ & $16(14.3)$ & 1 \\
\hline Other & $23(44.2)$ & $50(44.6)$ & 1 \\
\hline With ECMO $[N(\%)]$ & $22(42.3)$ & $38(33.9)$ & 0.523 \\
\hline With IABP [N (\%)] & $31(59.6)$ & $64(57.1)$ & 0.891 \\
\hline With BP $[N(\%)]$ & $3(58)$ & $17(15.2)$ & 0.194 \\
\hline
\end{tabular}

$T H$ therapeutic hypothermia, $C A G$ coronary angiography, $S D$ standard deviation, $I Q R_{t}$ interquartile range, $C P R$ cardiopulmonary resuscitation, $E C G$ electrocardiogram, $V F / V T$ ventricular fibrillation/pulseless ventricular tachycardia, $P E A$ pulseless electrical activity, $E C M O$ extracorporeal membrane oxygenation, $I A P B$ intra-aortic balloon pumping, $B P$ blood purification

$* N=37 ; * * N=87$

\section{a Patients with or without coronary treatment}

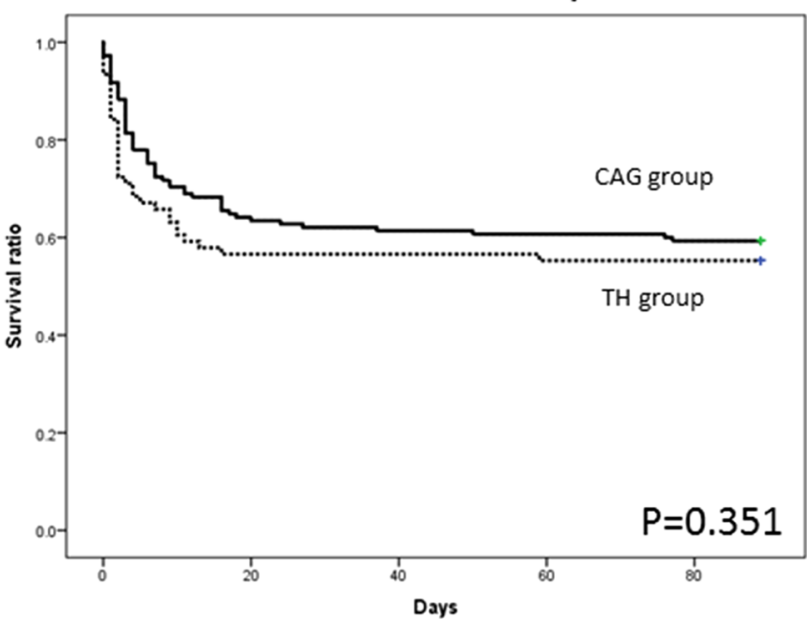

Fig. 2 a Kaplan-Meier curves of the TH group and CAG group with and without coronary artery treatment. There was no significant difference between the two groups (log-rank test). b Kaplan-Meier curves of the $\mathrm{TH}$ group and CAG group with coronary artery

\section{b Patients with coronary treatment}

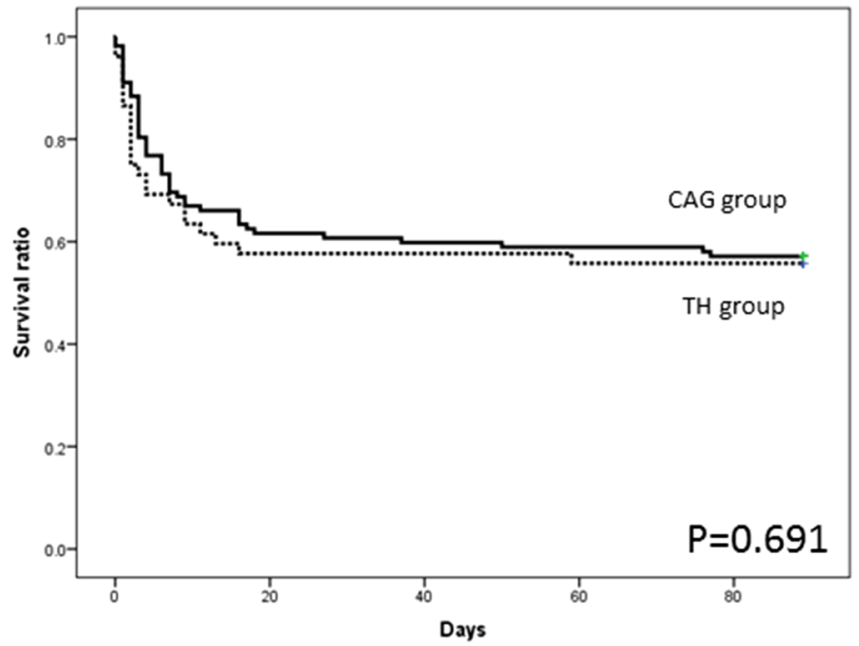

treatment. There is no significant difference between the two groups (log-rank test). TH Therapeutic hypothermia, CAG coronary angiography 
Table 3 Primary outcome: 90-day neurological situation

\begin{tabular}{lllllllll}
\hline & \multicolumn{2}{l}{ With and without coronary artery treatment } & & & With coronary artery treatment \\
\cline { 2 - 3 } & TH group $(N=76)$ & CAG group $(N=145)$ & $p$ & & TH group $(N=52)$ & CAG group $(N=112)$ & $p$ \\
\hline $\mathrm{CPC} 1+2[\mathrm{~N}(\%)]$ & $20(26.3)$ & $45(31.0)$ & 0.655 & & $14(26.9)$ & $26(23.2)$ & 0.709 \\
\hline
\end{tabular}

\section{Secondary outcomes}

The secondary outcomes are shown in Table 4.

Regardless of the coronary treatment, patients whose CPC are 1 or 2 are $23(30.3 \%)$ patients in the TH group, and $50(34.5 \%)$ patients in the CAG group in 30 days, respectively. Complications of hypothermia are seen in 24 $(31.6 \%)$ patients in the $\mathrm{TH}$ group, and 41 (28.3\%) patients in the CAG group between 90 days, and 3 (3.9\%) died from complications of hypothermia in the TH group, and $5(3.4 \%)$ were died in the CAG group.

Patients with coronary treatment, patients whose CPC were 1 or 2 are $17(32.7 \%)$ patients in the TH group, and $32(28.6 \%)$ patients in the CAG group in 30 days, respectively. The complications of hypothermia are seen in $22(42.3 \%)$ patients in the TH group, and in $29(25.9 \%)$ patients in the CAG group between 90 days. Two $(3.8 \%)$ died from complications of hypothermia in the TH group, and $3(2.7 \%)$ died in the CAG group.

There are no significant differences in the rate of good neurological prognosis at 30 days, complications of hypothermia, and death caused by complications of hypothermia between the two groups.

\section{Discussion}

All healthcare workers involved in emergency medicine have been trying to improve the prognosis of patients with cardiac arrest. Recently, it had been reported that hypothermia was an effective treatment to improve the neurological situation and survival of comatose patients after ROSC [1, 2], and the usefulness of hypothermia recommended in the 2005 AHA Guidelines for CPR and
ECC. Thereafter, the effectiveness of $\mathrm{TH}$ for comatose patients after ROSC has often been reported [15-17], and the 2010 AHA Guidelines for CPR and ECC recommended performing $\mathrm{TH}$ in comatose adult patients with ROSC after OHCA (class I-IIb) [3].

On the other hand, Spaulding et al. [4] report that accurate diagnosis by immediate CAG will yield suitable candidates for coronary angioplasty, and it seems to improve survival in patients with OHCA. Thereafter, the number of papers that reported the effectiveness of early CAG with potential coronary artery treatment in patients with ROSC after OHCA increased [4, 18-20], and the usefulness of early CAG and coronary artery treatment was described in the 2010 AHA Guidelines for CPR and ECC [3]. Recent reports have recommended both TH and CAG with coronary artery treatment $[17,21]$.

It seems to be ideal to start both $\mathrm{TH}$ and $\mathrm{CAG}$ in patients with OHCA immediately after arrival. However, there are doctors who concerned that there is an increase in pulmonary edema with the use of low-temperature infusion [7]. It is difficult for such doctors to start both TH and CAG at the same time. Additionally, all hospitals cannot always conduct immediate CAG for patients after ROSC. However, TH could be started if physicians experienced with TH after ROSC happen to be in the hospital. On the other hand, for CAG, cardiologists who are familiar with CAG are necessary. Many emergency physicians, cardiologists and intensivists have struggled with the clinical question of whether to start TH or CAG first after ROSC; however, there is no description about that in the 2010 AHA Guidelines for CPR and ECC. Therefore, we evaluated this point using data of the SOS-KANTO 2012 study.

We find that there are no statistically significant differences in survival and the 90-day neurological prognosis as

Table 4 Secondary outcome

\begin{tabular}{|c|c|c|c|c|c|c|}
\hline & \multicolumn{3}{|c|}{ With and without coronary artery treatment } & \multicolumn{3}{|c|}{ With coronary artery treatment } \\
\hline & $\begin{array}{l}\text { TH group } \\
(N=76)\end{array}$ & $\begin{array}{l}\text { CAG group } \\
(N=145)\end{array}$ & $p$ & $\begin{array}{l}\text { TH group } \\
(N=52)\end{array}$ & $\begin{array}{l}\text { CAG group } \\
(N=112)\end{array}$ & $p$ \\
\hline $\begin{array}{l}\text { 30-day neurological status } \mathrm{CPC} 1+2 \\
{[N(\%)]}\end{array}$ & $23(30.3)$ & $50(34.5 \%)$ & 0.672 & $17(32.7)$ & $32(23.6)$ & 0.729 \\
\hline $\begin{array}{l}\text { With complications of hypothermia } \\
{[N(\%)]}\end{array}$ & $24(31.6)$ & $41(28.3)$ & 0.768 & $22(42.3)$ & $29(25.9)$ & 0.177 \\
\hline Death caused by complications & $3(3.9)$ & $5(3.4)$ & 1 & $2(3.8 \%)$ & $3(2.7 \%)$ & 0.655 \\
\hline
\end{tabular}


primary outcomes, and in the 30-day neurological prognosis as the secondary outcome between the two groups regardless of coronary artery treatment. However, our finding that the survival rate tended to be better in the CAG group might have been influenced by type-II error because there were a small number of patients that were finally targeted for analysis. In addition, this result might indicate the importance of stabilizing hemodynamics first, so the survival curve of the CAG group may be better than that of the TH group without a statistical significant difference. On the other hand, Laver et al. [22] report that two-thirds of patients who die after OHCA die due to neurological injury and mortality is not associated with the ECG wave form of the cardiac arrest. In the present study, there is no significant difference in the 90-day neurological prognosis, and this result may have influenced the survival rate.

Regarding the secondary outcome, there are no significant differences in the rate of complications associated with hypothermia. This indicates that CAG can be performed safely with $\mathrm{TH}$.

Temperature management for patients after ROSC is important. In this study we could not discern what temperature of hypothermia is best. The report of TTM trial investigators mentions that there are no significant differences between 33 and $36{ }^{\circ} \mathrm{C}$ in patients who are treated with temperature management after ROSC [23]. In their report, the Kaplan-Meier curves of both groups are almost same. On the other hand, Kaplan-Meier curve of the CAG group is better than the TH group (of course there is no significant difference as pointed out above), so there is a possibility that CAG first produces a better outcome than TH first in OHCA patients.

\section{Limitations}

The SOS-KANTO study 2012 was a large, prospective cohort study of OHCA; however, the number of patients who underwent both $\mathrm{TH}$ and CAG was small, and this was only an observational study. This study did not include all hospitals with an emergency center in the KANTO area in Japan, and there is a possibility that our results are influenced by type-II error. There may have been differences in the indication to perform CAG and coronary artery treatment among the hospitals. In addition, the methods and apparatus for $\mathrm{TH}$ were varied and not unified. Therefore, a randomized double-blind trial would be preferable.

\section{Conclusion}

Whether TH or CAG was performed earlier did not affect the survival and neurological prognosis after 90 days and 30-day neurological prognosis among patients with ROSC after OHCA. Regarding the priority of TH or CAG, either TH or CAG can be immediately started in the hospital for comatose patients with ROSC after OHCA.

Author Contributions SOS-KANTO 2012 Steering CouncilYokohama City University Medical Center, Kanagawa (President, Naoto Morimura, MD); Nihon University School of Medicine, Tokyo (Director, Atsushi Sakurai, MD); National Cerebral and Cardiovascular Center Hospital, Osaka (Director, Yoshio Tahara, MD); Tokyo Women's Medical University Hospital, Tokyo (Arino Yaguchi, MD); Nihon University Surugadai Hospital, Tokyo (Ken Nagao, MD); Nippon Medical School Hospital, Tokyo (Tagami Takashi, MD); Japanese Red Cross Maebashi Hospital, Gunma (Dai Miyazaki, MD); National Disaster Medical Center, Tokyo (Tomoko Ogasawara, MD); Keio University Hospital, Tokyo (Kei Hayashida, MD, Masaru Suzuki, MD); Tokai University School of Medicine, Kanagawa (Mari Amino, MD); Kimitsu Chuo Hospital, Chiba (Nobuya Kitamura, MD); Juntendo University Nerima Hospital, Tokyo (Tomohisa Nomura, MD); Tokyo Metropolitan Children's Medical Centre, Tokyo (Naoki Shimizu, MD); Tokyo Metropolitan Bokutoh Hospital, Tokyo (Akiko Akashi, MD), National Center of Neurology and Psychiatry, Tokyo, Japan (Naohiro Yonemoto, DPH). SOS-KANTO 2012 Study Group-Tokai University School of Medicine (Sadaki Inokuchi, MD); St. Marianna University School of Medicine, Yokohama Seibu Hospital (Yoshihiro Masui, MD); Koto Hospital (Kunihisa Miura, MD); Saitama Medical Center Advanced Tertiary Medical Center (Haruhiko Tsutsumi, MD); Kawasaki Municipal Hospital Emergency and Critical Care Center (Kiyotsugu Takuma, MD); Yokohama Municipal Citizen's Hospital (Ishihara Atsushi, MD); Japanese Red Cross Maebashi Hospital (Minoru Nakano, MD); Juntendo University Urayasu Hospital (Hiroshi Tanaka, MD); Dokkyo Medical University Koshigaya Hospital (Keiichi Ikegami, MD); Hachioji Medical Center of Tokyo Medical University (Takao Arai, MD); Tokyo Women's Medical University Hospital (Arino Yaguchi, MD); Kimitsu Chuo Hospital (Nobuya Kitamura, MD); Chiba University Graduate School of Medicine (Shigeto Oda, MD); Saiseikai Utsunomiya Hospital (Kenji Kobayashi, MD); Mito Saiseikai General Hospital (Takayuki Suda, MD); Dokkyo Medical University (Kazuyuki Ono, MD); Yokohama City University Medical Center (Naoto Morimura, MD); National Hospital Organization Yokohama Medical Center (Ryosuke Furuya, MD); National Disaster Medical Center (Yuichi Koido, MD); Yamanashi Prefectural Central Hospital (Fumiaki Iwase, MD); Surugadai Nihon University Hospital (Ken Nagao, MD); Yokohama Rosai Hospital (Shigeru Kanesaka, MD); Showa General Hospital (Yasusei Okada, MD); Nippon Medical School Tamanagayama Hospital (Kyoko Unemoto, MD); Tokyo Women's Medical University Yachiyo Medical Center (Tomohito Sadahiro, MD); Awa Regional Medical Center (Masayuki Iyanaga, MD); Todachuo General Hospital (Asaki Muraoka, MD); Japanese Red Cross Medical Center (Munehiro Hayashi, MD); St. Luke's International Hospital (Shinichi Ishimatsu, MD); Showa University School of Medicine (Yasufumi Miyake, MD); Totsuka Kyoritsu Hospital (Hideo Yokokawa, MD); St. Marianna University School of Medicine (Yasuaki Koyama, MD); National Hospital Organization Mito Medical Center (Asuka Tsuchiya, MD); Tokyo Metropolitan Tama Medical Center (Tetsuya Kashiyama, MD); Showa University Fujigaoka Hospital (Munetaka Hayashi, MD); Gunma University Graduate School of Medicine (Kiyohiro Oshima, MD); Saitama Red Cross Hospital (Kazuya Kiyota, MD); Tokyo Metropolitan Bokutoh Hospital (Yuichi Hamabe, MD); Nippon Medical School Hospital (Hiroyuki Yokota, MD); Keio University Hospital (Shingo Hori, MD); Chiba Emergency Medical Center (Shin Inaba, MD); Teikyo University 
School of Medicine (Tetsuya Sakamoto, MD); Japanese Red Cross Musashino Hospital (Naoshige Harada, MD); National Center for Global Health and Medicine Hospital (Akio Kimura, MD); Tokyo Metropolitan Police Hospital (Masayuki Kanai, MD); Medical Hospital of Tokyo Medical and Dental University (Yasuhiro Otomo, MD); Juntendo University Nerima Hospital (Manabu Sugita, MD); Nihon University School of Medicine (Kosaku Kinoshita, MD); Toho University Ohashi Medical Center (Takatoshi Sakurai, MD); Saiseikai Yokohamashi Tobu Hospital (Mitsuhide Kitano, MD); Nippon Medical School Musashikosugi Hospital (Kiyoshi Matsuda, MD); Tokyo Rosai Hospital (Kotaro Tanaka, MD); Toho University Omori Medical Center (Katsunori Yoshihara, MD); Hiratsuka City Hospital (Kikuo Yoh, MD); Yokosuka Kyosai Hospital (Junichi Suzuki, MD); Saiseikai Yokohamashi Nambu Hospital (Hiroshi Toyoda, MD); Nippon Medical School Chiba Hokusoh Hospital (Kunihiro Mashiko, MD); Tokyo Metropolitan Children's Medical Centre (Naoki Shimizu, MD); National Medical Center for Children and Mothers (Takashi Muguruma, MD); Chiba Aoba Municipal Hospital (Tadanaga Shimada, MD); Kuki General Hospital (Yoshiro Kobe, MD); Matsudo City Hospital (Tomohisa Shoko, MD); Japanese Red Cross Narita Hospital (Kazuya Nakanishi, MD); Tokyo Bay Urayasu/Ichikawa Medical Center (Takashi Shiga, MD); NTT Medical Center Tokyo (Takefumi Yamamoto, MD); Tokyo Saiseikai Central Hospital (Kazuhiko Sekine, MD); Fuji Heavy Industries Health Insurance Society OTA Memorial Hopital (Shinichi Izuka, MD). (http://www. jaam- kanto.jp/sos_kanto/sos_kanto2012_contributors.html).

Funding Sources This study was supported by Japanese Association for Acute Medicine of Kanto.

\section{Compliance with ethical standards}

Conflict of interest The authors declare that they have no conflict of interest.

Statement of human and animal rights All procedures performed in studies involving human participants were in accordance with the ethical standards of the intstitutional or national resarch committee, and with the 1964 Helsinki declaration and its later amendments or comparable ethical standards.

Informed consent The protocol of this study was approved without the need for informed consent by the research ethics board of Yokohama City University Medical Center (Yokohama, Kanagawa, Japan).

Open Access This article is distributed under the terms of the Creative Commons Attribution 4.0 International License (http://crea tivecommons.org/licenses/by/4.0/), which permits unrestricted use, distribution, and reproduction in any medium, provided you give appropriate credit to the original author(s) and the source, provide a link to the Creative Commons license, and indicate if changes were made.

\section{Appendix}

The SOS-KANTO 2012 study group members: Shuichi Hagiwara, Kiyohiro Oshima, Kei Hayashida, Atushi Sakurai, Yoshio Tahara, Ken Nagao, Naohiro Yonemoto, Arino Yaguchi, and Naoto Morimura.

\section{References}

1. Hypothermia after cardiac arrest study group (2002) Mild therapeutic hypothermia to improve the neurologic outcome after cardiac arrest. N Engl J Med 346:549-556. doi:10.1056/ NEJMoa012689

2. Bernard SA, Gray TW, Buist MD, Jones BM, Silvester W, Gutteridge G, Smith K (2002) Treatment of comatose survivors of out-of-hospital cardiac arrest with induced hypothermia. N Engl J Med 346:557-563. doi:10.1056/NEJMoa003289

3. Peberdy MA, Callaway CW, Neumar RW, Geocadin RG, Zimmerman JL, Donnino M, Gabrielli A, Silvers SM, Zaritsky AL, Merchant R, Vanden Hoek TL, Kronick SL (2010) Part 9: postcardiac arrest care:2010 American heart association guidelines for cardiopulmonary resuscitation and emergency cardiovascular care. Circulation 122:S768-S786. doi:10.1161/CIRCULATIO NAHA. 110.971002

4. Spaulding CM, Joly LM, Rosenberg A, Monchi M, Weber SN, Dhainaut JF, Carli P (1997) Immediate coronary angiography in survivors of out-of-hospital cardiac arrest. N Engl J Med 336:1629-1633. doi:10.1056/NEJM199706053362302

5. Reynolds JC, Callaway CW, El Khoudary SR, Moore CG, Alvarez RJ, Rittenberger JC (2009) Coronary angiography predicts improved outcome following cardiac arrest: propensity-adjusted analysis. J Intensive Care Med 24:179-186. doi:10.1177/ 0885066609332725

6. Sunde K, Pytte M, Jacobsen D, Mangschau A, Jensen LP, Smedsrud C, Draegni T, Steen PA (2007) Implementation of a standardized treatment protocol for post resuscitation care after out-of-hospital cardiac arrest. Resuscitation 73:29-39. doi:10. 1016/j.resuscitation.2006.08.016

7. Kim F, Nichol G, Maynard C, Hallstrom A, Kudenchuk PJ, Rea T, Copass MK, Carlbom D, Deem S, Longstreth WT Jr, Olsufka M, Cobb LA (2014) Effect of prehospital induction of mild hypothermia on survival and neurological status among adults with cardiac arrest: a randomized clinical trial. JAMA 311(1):45-52. doi:10.1001/jama.2013.282173

8. SOS-KANTO study group (2015) Changes in pre- and in-hospital management and outcomes for out-of-hospital cardiac arrest between 2002 and 2012 in Kanto, Japan: the SOS-KANTO 2012 Study. Acute Med Surg 2:225-233. doi:10.1002/ams2.102

9. SOS-KANTO study group (2015) Changes in treatments and outcomes among elderly patients with out-of-hospital cardiac arrest between 2002 and 2012: a post hoc analysis of the SOSKANTO 2002 and 2012. Resuscitation 97:76-82. doi:10.1016/j. resuscitation.2015.09.379

10. Kitamura N, Nakada TA, Shinozaki K, Tahara Y, Sakurai A, Yonemoto N, Nagao K, Yaguchi A, Morimura N (2015) Subsequent shock deliveries are associated with increased favorable neurological outcomes in cardiac arrest patients who had initially non-shockable rhythms. Crit Care 19:322. doi:10.1186/s13054015-1028-0

11. Amino M, Inokuchi S, Nagao K, Nakagawa Y, Yoshioka K, Ikari Y, Funakoshi H, Hayakawa K, Matsuzaki M, Sakurai A, Tahara Y, Yonemoto N, Yaguchi A, Morimura N (2015) Nifekalant hydrochloride and amiodarone hydrochloride result in similar improvements for 24-hour survival in cardiopulmonary arrest patients: the SOS-KANTO 2012 study. J Cardiovasc Pharmacol 66:600-609. doi:10.1097/FJC.000000000000310

12. Cummins RO, Chamberlain DA, Abramson NS, Allen M, Baskett PJ, Becker L, Bossaert L, Delooz HH, Dick WF, Eisenberg MS, Evans TR, Holmberg S, Kerber R, Mullie A, Ornat JP, Sandoe E, Skulberg A, Tunstall-Padoe H, Swanson R, Thies WH (1991) Recommended guidelines for uniform reporting of data from out- 
of-hospital cardiac arrest: the Utstein Style. A statement for health professionals from a task force of the American Heart Association, the European Resuscitation Council, the Heart and Stroke Foundation of Canada, and the Australian Resuscitation Council. Circulation 84:960-975. doi:10.1161/01.CIR.84.2.960

13. Jacobs I, Nadkarni V, Bahr J, Berg RA, Billi JE, Bossaert L, Cassan P, Coovadia A, D'Este K, Finn J, Halperin H, Handley A, Herlitz J, Hickey R, Idris A, Kloeck W, Larkin GL, Mancini ME, Mason P, Mears G, Monsieurs K, Montgomery W, Morley P, Nichol G, Nolan J, Okada K, Perlman J, Shuster M, Steen PA, Sterz F, Tibballs J, Timerman S, Truitt T, Zideman D (2004) Cardiac arrest and cardiopulmonary resuscitation outcome reports: update and simplification of the Utstein templates for resuscitation registries: a statement for healthcare professionals from a task force of the International Liaison Committee on Resuscitation (American Heart Association, European Resuscitation Council, Australian Resuscitation Council, New Zealand Resuscitation Council, Heart and Stroke Foundation of Canada, Inter American Heart Foundation, Resuscitation Councils of Southern Africa). Circulation 110:3385-3397. doi:10.1161/01. CIR.0000147236.85306.15

14. Kanda Y (2013) Investigation of the freely-available easy-to-use software "EZR" (Easy R) for medical statistics. Bone Marrow Transplant 48:452-458. doi:10.1038/bmt.2012.244

15. Kern KB (2012) Optimal treatment of patients surviving out-ofhospital cardiac arrest. JACC Cardiovasc Interv 5:597-605. doi:10.1016/j.jcin.2012.01.017

16. Zimmermann S, Flachskampf FA, Schneider R, Dechant K, Alff A, Klinghammer L, Rittger H, Achenbach S (2013) Mild therapeutic hypothermia after out-of-hospital cardiac arrest complicating ST-elevation myocardial infarction: long-term result in clinical practice. Clin Cardiol 36:414-421. doi:10.1002/clc.22131

17. Stub D, Hengel C, Chan W, Jackson D, Sanders K, Dart AM, Hilton A, Pellegrino V, Shaw JA, Duffy SJ, Bernard S, Kaye DM (2011) Usefulness of cooling and coronary catheterization to improve survival in out-of hospital cardiac arrest. Am J Cardiol 107:522-527. doi:10.1016/j.amjcard
18. Cronier $\mathrm{P}$, Vignon $\mathrm{P}$, Bouferrache $\mathrm{K}$, Aegerter $\mathrm{P}$, Charron $\mathrm{C}$, Templier F, Castro S, El Mahmoud R, Lory C, Pichon N, Dubourg O, Vieillard-Baron A (2011) Impact of routine percutaneous coronary intervention after out-of-hospital cardiac arrest due to ventricular fibrillation. Crit Care 2011 15:R122. doi:10. $1186 / \mathrm{cc} 10227$

19. Callaway CW, Schmicker RH, Brown SP, Albrich JM, Andrusiek DL, Aufderheide TP, Christenson J, Daya MR, Falconer D, Husa RD, Idris AH, Ornato JP, Rac VE, Rea TD, Rittenberger JC, Sears G, Stiell IG (2014) Early coronary angiography and induced hypothermia are associated with survival and functional recovery after out-of-hospital cardiac arrest. Resuscitation 85:657-663. doi:10.1016/j.resuscitation.2013.12.028

20. Vaillant C, Leurent G, Garlantezec R, Thebault C, Martins R, Bot E, Coudert I, Boulmier D, Le Breton H, Bedossa M (2013) Coronary angioplasty is associated with a better nerurological outcome in the era of modern management if out-of-hospital cardiac arrest. Int J Cardiol 169:e91-e92. doi:10.1016/j.ijcard. 2013.10.037

21. Dumas F, White L, Stubbs BA, Cariou A, Rea TD (2012) Longterm prognosis following resuscitation from out of hospital cardiac arrest. J Am Coll Cardiol 60:21-27. doi:10.1016/j.jacc

22. Laver S, Farrow C, Turner D, Nolan J (2004) Mode of death after admission to an intensive care unit following cardiac arrest. Intensive Care Med 30:2126-2128. doi:10.1007/s00134-0042425-Z

23. Nielsen N, Wetterslev J, Cronberg T, Erlinge D, Gasche Y, Hassager C, Horn J, Hovdenes J, Kjaergaard J, Kuiper M, Pellis T, Stammet P, Wanschcher M, Wise MP, Aneman A, Al-Subaie N, Boesgaard S, Bro-Jeppesen J, Brunetti I, Bugge JF, Hingston CD, Juffermans NP, Koopmans M, Kober L, Langorgen J, Lilja G, Moller JE, Rundgren M, Rylander C, Smid O, Werer C, Winkel P, Friberg H (2013) Target temperature management at $33{ }^{\circ} \mathrm{C}$ versus $36{ }^{\circ} \mathrm{C}$ after cardiac arrest. $\mathrm{N}$ Engl J Med 369:2197-2206. doi:10.1056/NEJMoa1310519 